\title{
NSF board is urged to act more openly...
}

[WASHINGTON] The US National Science Board (NSB) is under fire for allegedly failing to adhere to laws intended to make the workings of the US government as open as possible to the public and the press.

John Holmfeld, a freelance journalist and former senior staff member at the House Science Committee, says the board has retreated from its obligations under the 1976 Government in the Sunshine Act. It has defied the act, Holmfeld says, "by conducting almost all of its substantive activities in committees, task forces, and other subgroups that are not open" to the public or the press.

Holmfeld is a veteran observer of the NSB and of the National Science Foundation (NSF), the grant-giving agency it oversees. He recalls that the board initially responded to the act by holding lengthy open sessions in which current and planned NSF projects and programmes were debated.

But in recent years, he says, the real discussion has taken place in closed committees, followed by cursory discussion in open session. For example, he claims that status reports on projects are rarely aired at public sessions of the science board.

He cites a meeting in February 1996, which followed a closed session of the board's Committee for Programs and Plans.
The chairman simply told the full board that "the committee received status reports on the Laser Interferometer Gravitational Wave Observatory, Gemini, Greenbank, Arecibo, the National High Magnetic Field Laboratory, and on NSF management and oversight of the National Center for Atmospheric Research and the academic research fleet".

NSB officials argue that discussions often involve budget and personnel matters that must be confidential. But Holmfeld's view is shared by the small band of reporters who regularly cover NSB meetings.

Some suspect that the committees are used to avoid public discussion of troubled projects, or to avoid public arguments between board members. Earlier this year, for example, the press were kept out for more than an hour while board members haggled over the wording of a public statement resisting the establishment of a National Institute for the Environment within the NSF.

Richard Zare, professor of chemistry at Stanford University and the previous chair of the board, says it needs private discussion for its executive functions. "We have to make decisions that cut programmes, and these couldn't be made in open session," he says.

The board would "get in huge trouble" if it discussed the NSF budget proposal openly

\section{....as head seeks to spread the word on grants}

[WASHINGTON] Rita Colwell, the new director of the National Science Foundation (NSF), said last week that many good scientists "feel cut out" by the agency because they are unfamiliar with its grant procedures.

Colwell told a meeting of the National Science Board, the agency's governing body, that some people who fail to get NSF grants "really don't know the culture" of the agency. "They have never sat on a peer-review committee," she said.

She pledges to inform scientists better about how the agency works. But Colwell denies that her comments imply that the NSF, which funds most US non-biomedical university research, is funding the wrong research. "I take a large and broad view" of whom the agency should support, she says.

Colwell says her concern arose during discussions with the principal investigator of a group that had what she considered to be an excellent proposal rejected by the agency.

Colwell's comments mark something of a departure for the agency, which prides itself on distributing grants purely on the basis of scientific merit, without regard to the circumstances of those submitting applications. They suggest that she intends to respond to critics of the agency including congressional representatives of small states - who complain that too much of its money goes to a few élite research universities.

Colwell is the first woman and the second life scientist to lead the agency. She is expected to emphasize opening up the NSF to a broader constituency of scientists and to support more multi-disciplinary work.

"This place can change," she told the science board. "It can react very quickly, and I'm delighted about that."

Joe Bordogna, the deputy director, is leading a task force to review the existing programmes targeting women and minorities, which cost $\$ 110$ million. The agency is likely to replace some or all of these with an approach to encourage diversity across all of its work.

Agency officials hope the review will protect affirmativeaction programmes from legal challenge - US courts have recently deemed programmes based on race to be illegal - while raising their effectiveness. The NSF is believed to be studying an approach to help minority and women postdoctoral researchers, for example, by tracking the progress of such researchers that it sponsors.

C. $\mathbf{M}$.

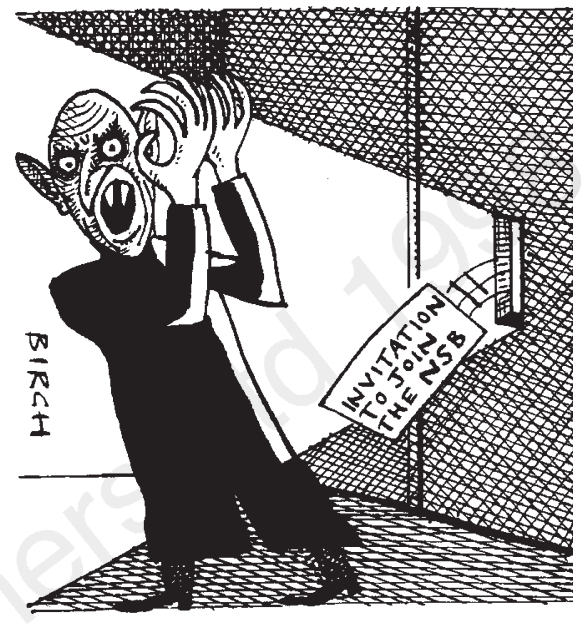

before its publication. "We had more open discussion time when I was chair than before," says Zare. Rita Colwell, the director of the National Science Foundation, agrees. "The board is much more open now than when I was a member in the 1980s," she says.

The previous director of the NSF, Neal Lane, who is now President Bill Clinton's science adviser, concedes that there is room for improvement in the balance between closed and open business at board meetings. "When I was there my sense was that it was uneven: we didn't always have the balance right," he says.

Eamon Kelly, president of Tulane University and the new chairman of the board, said last week that he was not familiar with Holmfeld's complaint, but pledged to look into it.

The impact of the US 'sunshine' laws has receded since the initial burst of illumination accompanying their enactment in 1976. At some agencies, public scrutiny serves to maintain openness. At the National Institutes of Health, for example, drug companies and disease advocacy groups work in close alliance to maximize public discussion at advisory panel meetings.

Similarly, at the Department of Energy, bodies such as the High Energy Physics Advisory Panel have a long tradition of fairly open discussion. (As purely advisory committees with no executive functions, these fall under the Federal Advisory Committee Act, a different statute from that governing the NSB.)

But the NSB has never been challenged on its interpretation of the sunshine laws. Dan Greenberg, the former editor of Science and Government Report, took legal action to open up meetings of scientists advising the US president. He says that the NSB is not influential enough to warrant such a challenge.

Holmfeld disagrees. It is "unfortunate and counterproductive" that the board does not conduct more of its business in public, he says, particularly as Lane is "talking about the importance of the public understanding of science".

ColinMacilwain 